\title{
The Impact of Financial Crisis on Insurance Sector and the Regulatory Response
}

\author{
Nurul Syuhada Zaidi, Nazaria Md Aris and Suzila Mohamed Yusof \\ Faculty of Economics and Business, Universiti Malaysia Sarawak (UNIMAS)
}

\begin{abstract}
This paper aims to discuss what happen during the 2008 financial crisis and the reason behind it. This paper also aims to analyze the impact of the financial crisis to insurance sector and how they react. This paper also discussed the Solvency II (applied by the European Commission) as well as the Malaysian Risk-Based Capital. Lastly, this paper also provides some observation and suggestion on how similar crisis can be avoided in the future as well as ways to improve the regulations.
\end{abstract}

Keywords: risk management, insurance, Solvency II, Risk-Based capital

\section{INTRODUCTION}

In the early 2008, the stress in the insurance industry first came to light. It began with the discovery of huge size of subprime loans for housing in the United States. Bank has been lending money which they did not have to house buyers who could not pay. To ensure the loans remain good, they bundle them and insured the risk with big insurance companies such as AIG, and secondary mortgage companies. When huge number of house buyers could not pay, the system collapsed. Pressures increased with the downfall of Bear Stearns and intensified with the bankruptcy of Lehman Brothers and the bailout of AIG which then triggered the global financial crisis. During this time, many financial institution and insurance companies faced with several challenges. Following the financial crisis, all organizations are taking greater interest in risk and risk management. Therefore, insurance companies responded by raising capital, increasing cash allocation and better improve the regulation.

This paper carefully examines the nature of insurance sector, what happen during the financial crisis and why, as well as its impact to insurance sector. This paper also provides some observations and suggestion how similar crises can be avoided in the future.

\section{The nature of insurance business}

Insurance companies have played very active and important role in the financial market as well as the economy as a whole. The main nature of an insurance company's business activity is by selling insurance products. This is where insured ${ }^{1}$ will transfer their risk to insurance company ${ }^{2}$ and insurer will promise to pay compensation to the insured in the event of any insurable event ${ }^{3}$ that might occur during the length of the insurance contract. In return, insured will promised to pay a constant stream of premiums to the insurance companies. It is for this reason that insurer need to carefully evaluate and underwrite the risk at stake while charging appropriate insurance premiums and calculate the amount of capital requirements that need to be set aside in order to cushion themselves against other losses in which sometimes can be catastrophic (Egidio dos Reis, A., Gaspar, R. M. \& Vicente, A. T., 2009). Generally, depending on the nature and amount of risk that an insurer is taking, insurer will decide on their capital requirement. Other than that, insurer also raised their profit by investing in the financial market. Insurance companies plays a big role as one of the natural player on financial market.

Insurance companies can be exposed to two main category of risk which were insurance risks and market risk (Egidio dos Reis, A., Gaspar, R. M. \& Vicente, A. T., 2009). Insurance risk are risk associated with the risk that may arise from the core business of the insurer activities such as wrong assessment of the risks insured, defaults from clients and counterparty risk from reinsurers. Besides since insurer is also an investor, therefore, they are exposed to the market risk as well. Market risk are 
risk that does not arise from the insurer main business activity but instead came from the insurer risky investment activity as an investor.

The insurance sector carries substantial importance since not only it helps to provide cover against various risks facing the people and companies as well as provide assistance in spreading the risk, nevertheless, they also support the economy to grow by being the key player in the investment sector that helps drive the economy of a country. On EU stock exchanges, the insurance sector is the largest institutional investor. It is essential, therefore, that we highlighted the significance of having a stable and solvent insurance sector. In the next section, we will discuss the financial crisis of 2007 and its impact on the insurance sector.

\section{The financial crisis and its impact on insurance sector}

The origin of the financial crisis of 2007 is said originated from the US housing market. As Hull (2009) has pointed out, there is a huge increase in subprime mortgage lending in the period of 2000 to 2006 . Mortgages that are considered to be significantly riskier than average is termed as subprime mortgage.

Figure 1: The Theory of CDO

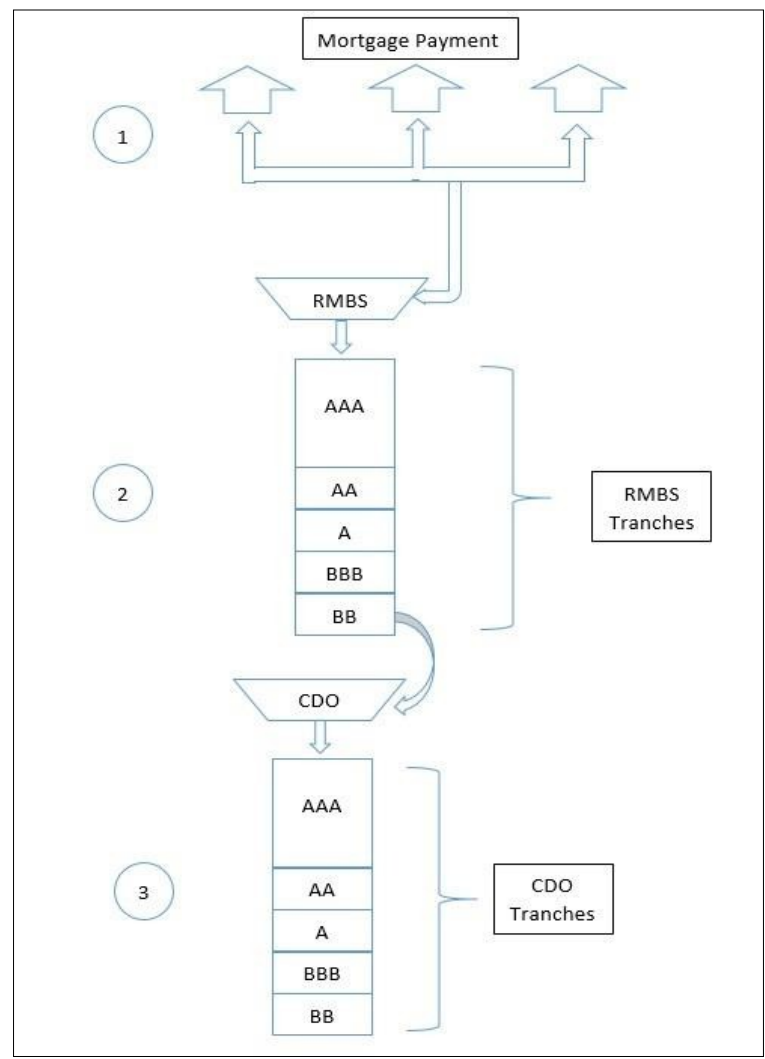

It begins when the mortgage payments (subprime loan) were packed together into Mortgage Backed Securities (MRBS) by the top Wall Street investment banks such as Goldman Sachs, Morgan Stanley and others, then grouped it into tranches by level of risk and earnings payment (refer to figure 1). The payment collected then renamed into Collateralized Debt Obligations (CDOs). The CDOs then was sold to investors as derivative securities. The CDOs were then rated by the allegedly "independent" rating agencies (example: Moody, S\&P and Fitch) who were hired by the investment banks themselves. The rating agencies rate the CDOs as high grade investments when in fact a lot of them comprised of high risk mortgage loans (subprime loan). Due to some limitation, to get more in depth details on the CDOs product and tranches, it is advisable to refer from Hull (2009) and Kherraz (2006) paper.

For one thing, it could be argued that there is a clear conflict of interest by the rating agencies and more 
controversial is the question as to whether there is any fraudulent act by banks who might give misleading information to their clients to get more money from these CDOs. In other words, they are giving the impression that the CDOs are secure investments since it received A-ratings, which in reality, it is not entirely true. As a result, the CDOs become popular among investors as well as retirement funds who held the life savings of millions of people who bought them.

Even though the starting point of the financial crisis is from the CDOs product, but there is a need to mention the role of large insurance companies like AIG to be another reason that amplify the financial crisis. AIG creates an illusion to investors who bought CDOs that their investments is secure by creating an insurance policies called Credit Default Swaps (CDS) which covers investors against potential losses in case the investment failed. In a Credit Default Swap contract, the protection seller agrees to make payment to protection buyer I the event the referenced entity experience a "credit event" such as bankruptcy or default. Initially, the CDS were used to transfer risk of owner of the bond to insurer. This make the product even more popular even though in the end make things messier. This is because, AIG even allowed investors to buy insurance and pay the insurance premium for a CDO that someone else own. Here, if the CDO investment went bad, investors can claim from insurance company the value of the CDO. This increase the speculation activities in the market.

Unfortunately, the question to highlight is that what is the reason AIG allowed investors to buy insurance on CDOs that they do not even own. In the end, the financial crisis begins to arise when the homeowners defaulted and have not enough money to pay off all the mortgage related securities.

Having said that, according to Schich (2009) some may view that the change in the bank business model is the main cause of the crisis where rather than holding loans until maturity on their own balance sheets, but instead they distribute the credit risks which also increase other additional risk. They come up with financial instrument that is so complex and hard to understand. While there is a different views that mentioned insurers did not contribute to the systemic issues that banks faced and did not initiated and repackaged the subprime mortgages, we cannot simply ignore the fact that insurer such as AIG also contribute to the illusion that the CDOs is a safe investment.

As Schich (2009) has pointed out, even though the financial crisis of 2007 originated from the housing bubbles and may mainly be a banking crisis, nonetheless, insurance companies have been affected as well in adverse ways. This is because of the role of the insurance companies as an investor, as the crisis spread and affected their investment portfolios. This is not a surprise as according to Schich (2009), their assets are largely held in bonds and stocks which instantaneously experience a valuation pressure during the crisis.

Other than from their investment activities, insurer is also effected during the financial crisis when the insurance product that they offer shows high number of claim and default (Schich, 2009). The most affected product besides the CDS, would be the securities offering liability insurance and the Directors and Officer's liability insurance.

The securities offering liability insurance covers the insured against any claims legally brought against him arising from incomplete, misleading or false information provided in a prospectus. Investors usually rely on information described in the prospectus whether to invest or not in the company. Sometimes, investors could suffer significant financial losses due to information provided in a prospectus being unintentionally inaccurate, incomplete or misleading.

During the late 2007, due to lack of confidence from investors, most companies suffered from difficulty in raising funds (Schich, 2009). The profitability described in their prospectus cannot be met and thus, many investors take legal actions to seek compensation for their losses. This in the end increase the loss frequency and insurer are forced to tighten their acceptance criteria and at the same time increase the average premiums.

While Director's and Officer's liability insurance covers insured against claims from any 
alleged or proved management error in their functions as directors and officers. The financial situation of a prospect is the key factor to determine the loss frequency and insurance coverage. From 2007, the economic turmoil has damaged a lot of financial health of firms around the world. As said by Schich, (2009), statistics shows that the worse the financial situation is, the higher the claim probability will be. The prospect is likely to face judicial proceedings to compensate the injured parties if any third party (e.g. shareholders) suffers a loss. But if the prospect cannot satisfy the indemnification obligations, injured third party will sue the prospect's directors and officers.

According to AIG, the number of annual claims nearly tripled from 2007 to 2009, putting insurer in a very difficult situation. In the end, insurers were forced to tighten the acceptance criteria of several insurance portfolios to limit their exposure by creating new endorsement. Yet, other insurance product was less affected by the economic crisis because the financial situation of their portfolios does not have an impact on their loss frequency, but it still affects the turnover and decrease the amount of premium collected by the insurer.

Having discussed the impact of financial crisis to insurance companies, the insurance sector does not appear to be threatened as a whole and it is also proven that insurance companies were well protected initially during the period of financial turbulence since they tend to have widely diversified portfolios and high focus on investment in high quality investment. Also, insurance companies are normally funded by a reasonably stable flow of premiums (life insurance premium which is usually long term), with very limited reliance on short term market funding. In this sense, the insurance sector acted as a stabilising factor at a time of considerable stress in the financial system considering that they were able to absorb market volatility due to the nature of their long term perspective. Furthermore, many insurance companies continue to provide insurance coverage against a variety of hazards, and they have the ability to reinvest the earnings in financial assets. Adding to the point, Schich (2009) also pointed out that because of the loss of confidence due to the financial crisis, as a result there is an increase in demand for several other insurance products which have some form of capital and/ or return guarantee.

In short, even though insurance sector is not affected severely as a whole, they were still affected in adverse ways. To put it simple, most of their losses are from their investment activities instead of their traditional core insurance activities. Yet, as compared to losses those of banks, investment losses of insurance companies appear to be much more limited. Jenkins (2013) has observed that after the financial crisis, people direct their focus more towards banks, but instead they should also give some attention to the insurance companies. All of the changes in the financial market presents new risks to insurance companies and investors. The fact that AIG asked for a bridge loan during the crisis in order to have enough time to raise funds and sell assets, this should sound the alarms as a useful reminder that insurer need proper regulation as well. Therefore, we will discuss in the next section on the regulation or also known as Solvency II, which has change the risk management and capital structure of insurance sector as a result of the financial crisis.

\section{THE SOLVENCY II FRAMEWORK}

While insurer as a whole were able to cushioned the impact of the financial crisis, there is still an immediate need to monitor the financial health of insurance companies as the crisis has clearly demonstrated that protection against systemic risks should also include monitoring and mitigating risk as well as having a firm and robust capital requirement. It is very important that insurance company are able to make sure that they have sufficient liquidity to meet its liability.

As a result of the previous market uproar, there is an increase awareness over the need to improve risk management and avoid the weaknesses of the previous system. The volatile financial market has put the insurance sector solvency and risk management under significant pressure. As a result, Solvency II is introduced to replace the existing and outdated Solvency I. Solvency II is the initiative to refurbish the capital adequacy of the European insurance industry and create an agreed set of capital and risk management requirements. It main purpose also include improving the protection of policyholders and their beneficiaries. Solvency II introduce new regulatory and supervisory framework for Europe's 
insurance industry (KPMG, 2011). Rather than focus on the management of single risks independently, Solvency II focuses more heavily on a more holistic risk management approach (Egidio dos Reis, A., Gaspar, R. M. \& Vicente, A. T., 2009). Solvency II also take into account the various insurance risks (underwriting risk, counterparty risk, operational risk).

Keep in mind that to date, Solvency II is not yet established and is still under scrutiny by supervisory authorities in each EU country and changes may still occur. Solvency II is believed to be in forced in January 2016. In general, this framework is divided into three pillars.

Figure 2: Solvency II Framework

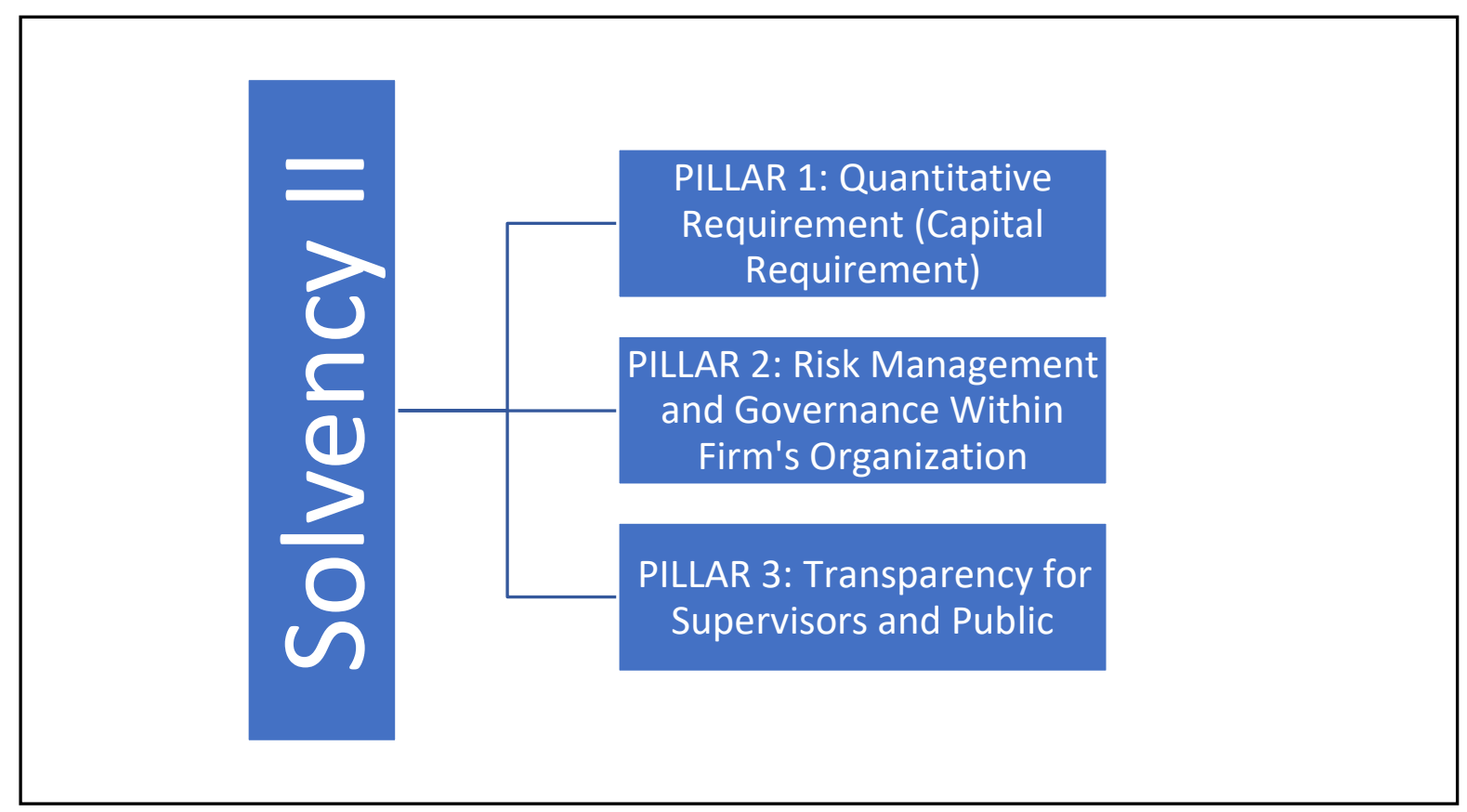

As figure above displays, Pillar 1 which covers all the quantitative requirements whereby it ensures firms are adequately capitalized with risk-based capital. It ensures the amount financial resources the company needs to hold in order to be considered solvent.

Two important capital requirements are defined, where the first one is known as the Solvency Capital Requirement (SCR), and another lower threshold called the Minimum Capital Requirement (MCR). The first action level (SCR), which is the supervisory action will be triggered if resources fall below its level. While MCR is a more severe action level by the control authority, where it can include company closure to new business. Even though companies may use either the standard formula approach or an internal formula approach, they all must make sure all valuation are done in prudent and market- consistent manner. For more detailed calculation on Pillar I solvency model, it is advised to refer to the Egidio, Gaspar \& Vicente (2009).

Next, although Pillar I focused more on quantitative requirements, Pillar 2 focus more towards higher standards of risk management and governance within a firm's organisation which is more qualitative and supplements the first pillar. It includes the Own Risk and Solvency Assessment (ORSA) where firms do their own self-assessment of its risks, in respect of capital requirements and sufficiency of capital resources.

While Pillar 3 targets for the higher level of transparency for supervisors and the public. Firms must increase the level of risk disclosure requirement and ensure firm's financial position is better explained and information is up to date.

Nevertheless, there are still some disagreements among stakeholders on Pillar I, whereby the framework should also recognise the nature of insurance business for their liabilities of long-term 
business. Since most of life insurance products offer longer maturity dates, hence it offers more value for money to policyholders. Some of the main reasons are, most life insurance product are helping policyholders in saving for their retirement and minimise the pension gap. Due to the carefulness in the underwriting process while choosing which risk to accept, the life insurance products are often more stable. It is also more predictable since insurance company can use mortality rate to predict the occurrence of insurable events or in the event of surrender of the policy, therefore information from historical data increase the confidence to predict a more accurate premium.

For policyholders, the main concern is whether the insurer is able to meet its obligations in the future. For that reason, insurance companies use Asset Liability Management (ALM) techniques to manage their income (assets) and promised outgoings to policyholders (liabilities). Since the main purpose of a matching adjustment is to protect against credit spread volatility, an increase in capital is desirable in order to match their liabilities. However, if the capital requirement of the company is increased excessively without taking into account the nature of their long term investment, and fail to extend the scope of the matching adjustment, this will have caused an increased in cost for policyholders and less product diversity.

For that reason, some changes may need to be considered to better reflect the nature of the insurance business. First of all, further analysis need to be made to take into account the product features of life insurance (long term). Since the insurance apply the Law of Large number, hence the portfolio makesit possible to predict policyholder behaviour (lapse of premium payment or surrender of policy) as well as predict the probability of occurrence of insured event. Insurer can also identify the corresponding assets associated with the cash flows and meet the requirements for the matching adjustment, for example bonds.

Figure 3: The Omnibus II Proposal

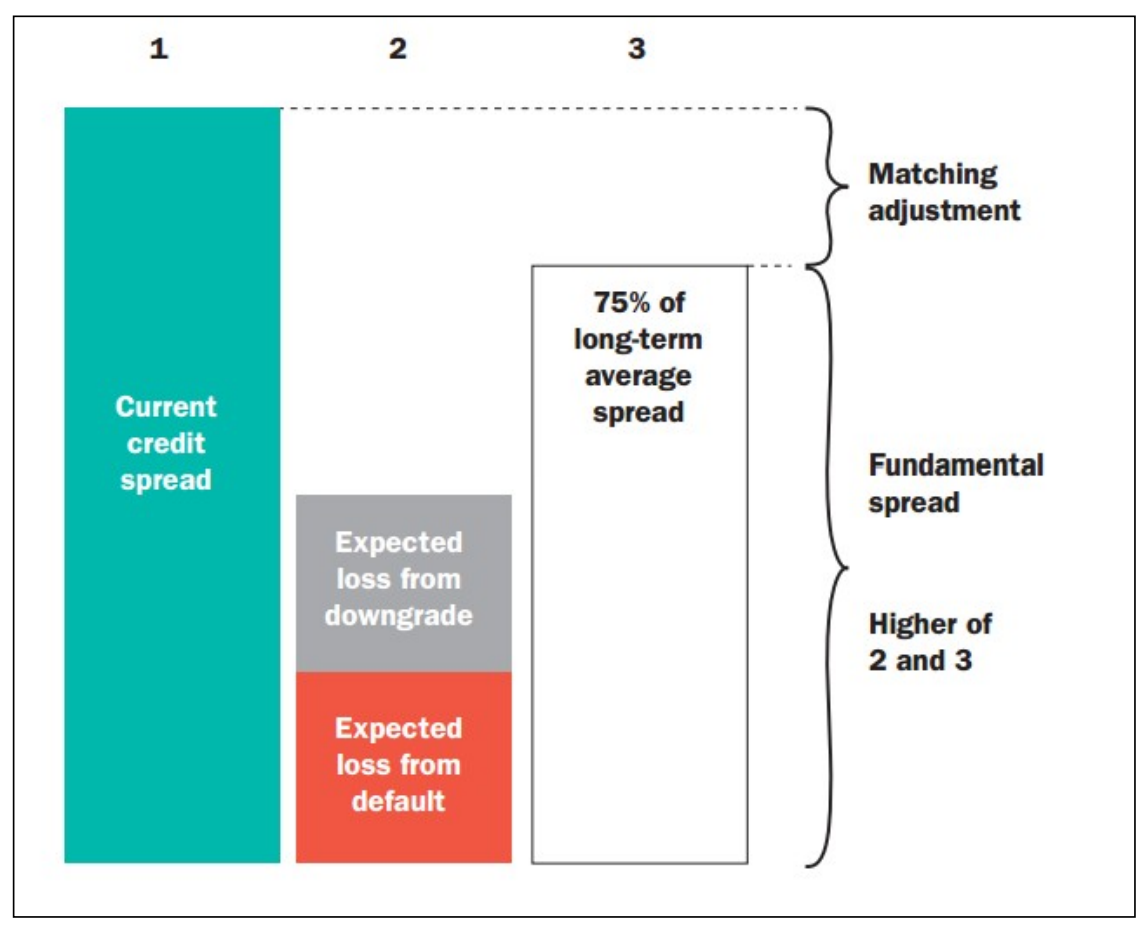

Due to the arguments amongst the authorities, a proposal has been presented which is also known as Omnibus II proposal (refer figure 3). With reference to the Omnibus II proposal the matching adjustment is the total of the Current Credit Spread minus the Fundamental Spread. The Fundamental spread is the expected loss on defaults plus the expected loss on downgrade but subject to a floor of $75 \%$ of the long term average spread. The potential loss from defaults can be determined and calculated using historical data of any default from policyholder. Due to this proposal, the Solvency II framework 
implementation has been delayed but is expected to come in force in January 2016.

Other than the noted already issues, according to KPMG (2011), some insurers are also uncertain about the Solvency II implementation in relation to the capital rules implementation due to the fear of disclosing either too much or too little information. Insurers wants to be able to manage expectations and educate the investors and analyst community before the Solvency II implementation.

In short, the unstable market condition in 2008 have proven that insurer was able to protect their assets throughout the economic cycle despite the turmoil. Because of the collapse of the major banks, people start looking for safer investment and look at life insurance as their safety net. An ALM framework can help give better insight in the firm's operation and profitability. It gives insight of the better understanding of the firm financial flows, the measurement and the management of interest rate risks. Asset Liability Management (ALM) and Strategic Asset Allocation (SAA) plays a critical role in managing liquidity and investment strategy processes. Further discussion in this paper would be the ALM and SAA process suggested by the Goldman Sachs Asset Management.

\section{MALAYSIAN RISK BASED CAPITAL FRAMEWORK}

In Malaysia, the insurance industry is under the supervision of Bank Negara Malaysia (BNM). They are regulated under different laws which were Malaysian Insurance Act (1996) and Malaysian Takaful Act (1984) depending on the nature of the business model (Yuzi, Lau, \& Farid, 2016). BNM has adopted a risk-based supervision approach in order to maintain the stability and financial soundness of Malaysian Insurance Industry (Lai, 2011).

Risk-based capital is defined as the minimum theoretical amount of capital based on the degree of risk taken by an insurance company that an insurer should hold to protect customers against adverse developments.

The Risk Based Capital (RBC) Framework for conventional insurers introduced in 2009 by Bank Negara Malaysia (BNM) concentrated on financial risks such as credit, market, underwriting and concentration risk.

Thus, in 2011, BNM introduced the enhanced RBC framework with broad risks to be managed. Based on the documents issued by BNM, the revised RBC focuses on credit risks (assets default and failure of counter-party), market risks (reduction in assets market value and non-parallel in asset-liability), liability risk (insurance liabilities underestimation and adverse claims experience) and operational risk (failed system and human capital process).

Further, in 2011, the first draft of Risk-Based Capital Guidelines for Takaful Operators was issued and took effect on 1 January 2014.

\section{RECOMMENDATION}

All market participants have access to relevant information (Papers, 2008). disclosure of sufficient risk management information to the market (Papers, 2008). There are many factors that contributed to the financial crisis in 2007. Therefore, how can future crisis be avoided and some suggestions were pointed out.

First of all, during the crisis, it can be seen that there are a lot of excessive risk taking in the market which eventually collapsed the housing market. Therefore, to avoid excessive risk taking, it is advisable for regulators to come up with a regulation where investors to keep at least some risk in their own book. This is to ensure that investors will be more responsible since they have some risk that they have to bear and thus they will become more careful.

Next, with respect of regulation. Due to the over reliance to credit rating agency, investors are convinced 
that their investment are safe, but in fact, it is not entirely safe. Investors as well as insurance companies in particular should do their own internal rating and regulation instead of only relying on only one entity which is the credit rating agency.

Other than that, transparency should also be further encouraged, not only in insurance sector but also in the market. Investors should have enclosed enough information and make in depth judgement when accepting risk from a complicated product.

Debt is a very dangerous and risky decision sometimes. Make sure investors know how much the own and how much they owe. Also it is suggested not to use debt (credit) to cover and /or produce another debt (credit). This is because, the amount of debt would be too large and difficult to measure.

Furthermore, a more reliable and holistic regulation is necessary to regulate the market in order to produce a more discipline market players. Solvency II is a great example. However, some changes need to be made with regards to the Pillar I where they need to take into consideration the insurance companies' long term business nature. Insurance company also need to be extra careful in understanding the risk that they accept and more reconsideration need to be consider in the CDS product that they offer. Regulation should also effectively penalize violators such as investors who knowingly sold investments to their clients but later betted against them without informing the same clients, and the rating agencies that miss-rated the subprime loan as grade $\mathrm{A}$.

Other than that, we should not also depend too much on mathematic model. Human judgement is important as well.

\section{CONCLUSION}

Insurance companies have played very active and important role in the financial market as well as the economy as a whole. Following the events in the world financial system during 2008, all organizations are taking a greater interest in risk management and capital adequacy. The Financial Crisis has resulted in the shift of attitudes towards risks on the regulatory and asset management. The crisis not only affected the banking sector but the insurance sector as well. Despite the fact that during the unstable market condition in 2008 have proven that insurer was able to protect their assets throughout the economic cycle despite the turmoil, safety steps should still be considered. Since the insurance business write insurance business in variety of areas, this factor helps them to generate premium incomes that appears to have help in stabilising their business.

Following the crisis, Solvency II was introduced to regulate control the exposure to financial uncertainty in insurance sector. However, some factors in Solvency II has to be reconsidered due to the nature of life insurance contract which is usually long term. Even though some insurers are still uncertain due to information that need to be disclosed, this can be resolved by having proper reporting analysis and method. It is important that a clear reporting and information is delivered. Furthermore, there is growing understanding that the explicit management of risks and capital allocation brings benefits. By taking proactive approach to risk management and asset management, insurance company can potentially improve and their operations can become more efficient since the event that might cause disruption has been identified in advance and reduced. Their process and asset management to meet their liabilities will be more effective since consideration have been given in the risk and asset management process. Investment strategy will be more effective and help to assist in having some better strategic decisions.

\section{REFERENCES}

Papers, T. G. (2008). A Critical Analysis of the Solvency II Proposals, (1995), 193-206. https://doi.org/10.1057/gpp.2008.2

Yuzi, A., Lau, W., \& Farid, A. (2016). A Critical Analysis of the Malaysian Risk-Based Capital Framework: A Comparison between General Insurance and Takaful, 8(4), 23-41.

Egidio dos Reis, A., Gaspar, R. M. \& Vicente, A. T. (2009) Solvency II - An important case in Applied VaR. [Online]. p.1-10. Available from: 
http://pascal.iseg.utl.pt/ alfredo/ftp/papers/solvency2.pdf. [Accessed: $21^{\text {st }}$ July 2015]

Goldman Sachs Asset Management. (2010). Revisiting the Role of Insurance Company ALM within a Risk Management Aramework. Available from: http://www.goldmansachs.com/gsam/docs/instgeneral/general_materials/whitepaper/wp revisit in g role of ins co alm.pdf. [Accessed: $14^{\text {th }}$ February 2015]

Hull, J. C. (2009). The Credit Crunch of 2007: What Went Wrong? Why? What Lesson Can Be Learned?

Jenkins, P. (2013). Insurers may be at the centre of the next big crisis. Financial Times. [Online] $26^{\text {th }}$ December. Available from: http://www.ft.com/home/uk. [Accessed: 20 ${ }^{\text {th }}$ July 2015]

Kherraz, A. (2006). The May 2005 correlation crisis: Did the model really fail?

KPMG International. (2011). Solvency II. [Online]. Available from: http://www.kpmg.com. [Accessed $17^{\text {th }}$ January 2015]

Schich, S. (2009). Insurance Companies and the Financial Crisis. OECD Journal: Financial Market Trends. [Online] (Vol.2009/2). p.1-31. Available from: http://www.oecd.org. [Accessed: $20^{\text {th }}$ July 2015]

Corresponding Author: Nurul Syuhada Zaidi can be contacted at znsyuhada@unimas.my 